\title{
PERSEPSI PASIEN TENTANG KUALITAS PELAYANAN DI PUSKESMAS AKREDITASI DAN NON AKREDITASI KABUPATEN BANGGAI
}

\author{
Risky Ekaputri ${ }^{1}$, Anwar $^{1}$, Nurhaedar Djafar ${ }^{3}$ \\ ${ }^{1}$ Universitas Muslim Indonesia \\ ${ }^{2}$ Universitas Muslim Indonesia \\ ${ }^{3}$ Universitas Muslim Indonesia
}

(Alamat Korespondensi: putridjalumang91@gmail.com/082291074109)

\begin{abstract}
ABSTRAK
Akreditasi merupakan upaya pelaksanaan dan peningkatan kualitas layanan, puskesmas. kualitas pelayanan dapat diukur dengan membandingkan antara pelayanan yang diharapkan dengan kinerja Pelayanan, kinerja pelayanan direfleksikan dengan apa yang diterima dan dirasakan (persepsi) pasien. Metode SERVQUAL membandingkan antara harapan dan persepsi pasien atas suatu pelayanan. Penelitian ini bertujuan untuk menganalisis persepsi pasien tentang kualitas pelayanan di puskesmas akreditas dan non akreditasi kabupaten banggai. Penelitian ini menggunakan cross sectional dengan teknik Purposive Sampling dan menggunakan uji regresi berganda dengan derajat kemaknaan $(\rho=0.05)$. Sampel penelitian adalah pasien rawat inap di 6 (enam) puskesmas (puskesmas kampung baru, kintom, batui, toili II, hunduhon dan tangeban yang berjumlah 121 sampel. Hasil penelitian dengan uji statistik regresi sederhana menunjukkan bahwa variabel kualitas pelayanan meliputi: assurance memiliki pengaruh terhadap presepsi pasien $(\rho=0,00)$, courtesy memiliki pengaruh terhadap presepsi pasien $(\rho=0,00)$. Berdasarkan hasil uji regresi berganda, didapatkan bahwa secara simultan variabel tangibles memiliki pengaruh lebih besar terhadap presepsi pasien di puskemas akreditasi dan non akredtasi kabupaten banggai.
\end{abstract}

Kata Kunci : Akreditasi, Kualitas Pelayanan, Persepsi Pasien

\section{PENDAHULUAN}

Dengan adanya UU Nomor 25 tahun 2009 tentang Pelayanan Publik dan UU Nomor 29 tahun 2004 tentang Praktik Kedokteran, maka semakin mendorong Puskesmas untuk memberikan pelayanan kepada masyarakat secara merata dan berkualitas. Untuk menjamin kualitas penyelenggaraan tersebut, maka pemerintah telah mengeluarkan Permenkes Nomor 46 tahun 2015 tentang Akreditasi FKTP. Melalui akreditasi FKTP ini diharapkan adanya proses perbaikan dan peningkatan kualitas pelayanan kesehatan berkesinambungan di FKTP. Penyelenggaraan akreditasi ini dilaksanakan oleh badan independent yang saat ini dilaksanakan oleh Komisi Akreditasi FKTP.

Kualitas pelayanan kesehatan sangat erat hubungannya dengan kepuasan penerima jasa pelayanan kesehatan dalam hal ini adalah pasien, karena kebanyakan penilaian para pengguna jasa pelayanan lebih mementingkan proses pelayanan kesehatan diabndingkan outcome. Atas dasar itu menjaga kualitas sebuah pelayanan kesehatan sangat ditentukan oleh kemampuan manajemen puskesmas, menjaga reputasi institusinya dan kepercayaan masyarakat sebaggai pengguna. Para dokter dan paramedic wajib terus menjaga dan mengasa keterampilan dan profesionalismenya sesuai dengan tingkat perkembangan teknologi kedokteran dan ekspektasi masyarakat. Dari uraian tersebut di atas, Parasuraman, Zeithhaml, dan berry menganalisis dimensi kualitas jasa dari sudut yang berbeda menggunakan lima aspek komponen kualitas tersebut dikenal dengan nama SERVQUAL dimana meliputi: Responsiveness (cepat tanggap), Reliability (tepat waktu dan akurat), Assurance (Jaminan Kualitas), Empathy (Kepedulian dan perhtian), Tangible (Fasilitas Fisik) (Wardani Ratna, 2017).

Berdasarkan profil kesehatan Indonesia tahun 2017 Jumlah Puskesmas Menurut Provinsi tahun 2017, Provinsi Sulawesi tengah mempunyai jumlah puskesmas berjumlah 193 puskesmas dengan jumlah kecamatan sebanyak 175 kecamatan yang terdiri dari 12 kabupaten/kota yang ada di provinsi Sulawesi tengah. Berdasarkan data profil kesehatan tahun 2017 Puskesmas yang Memberikan Pelayanan Sesuai Standar pada Tahun 2017 di Provinsi Sulawesi Tengah dari jumlah 12 kabupaten/kota dengan Puskesmas yang Sesuai Standar sebanyak 74 Puskesmas dari 193 puskesmas yang ada, maka ada 119 puskesmas disetiap kecamatan yang tersebar di kabupaten/kota yang belum sesuai standar pelayanan kesehatan yang ada. Dengan hasil 
lebih banyak puskesmas yang belum sesuai standar maka puskesmas yang ada di wilayah provinsi Sulawesi tengah belum secara merata memberikan pelayanan yang prima bagi masyarakat, masih perlu untuk meningkatkan pelayanan puskesmas.

\section{BAHAN DAN METODE}

\section{Lokasi, Populasi dan Sampel}

Peneliti akan meneliti 6 (enam) puskesmas yang ada di kab. Banggai yang terdiri dari puskesmas yang belum terakreditasi, terakreditasi dasar, dan terakreditasi madya. Sampel dalam penelitian ini adalah jumlah dari keseluruhan pasien rawat inap dipilih dengan teknik purposive sampling, yaitu 121 responden dan dipilih secara random sampling. Adapun syarat yang ditentukan adalah responden pasien yang bisa berkomunikasi dan bersedia untuk diwawancarai. Responden dalam penelitian ini yaitu responden pada pasien rawat inap. Sampel dalam penelitian ini adalah seluruh populasi pasien rawat inap perbulan (total populasi) dengan tekhnik pengambilan sampel yaittu purposive sampling dimana sampel merupakan responden yang di dapatkan pada saat penelitian dilakukan yaitu pada bulan novemeber-desember 2018.

\section{Pengumpulan Data}

1. Data Primer

Data Primer dikumpulkan dengan cara melakukan observasi dan wawancara langsung dengan pasien puskesmas kab. banggai berdasarkan daftar pertanyaan yang telah tersedia.

2. Data Sekunder

Data Sekunder diperoleh dari hasil pencatatan dan pelaporan dari petugas kesehatan di puskesmas kab banggai

\section{Analisis data}

1. Analisa Bivariat untuk mengetahui pengaruh dua variable yaitu variable independent dan variable dependent menggunakan uji regresi dengan bantuan alat SPSS. Uji regresi dimaksudkan untuk menentukan apakah terjadi pengaruh yang bermakana antara variable independent dan variable dependent, maka menggunakan $\rho$ (Value) dibandingkan dengan tingkat kesalahan yang digunakan $5 \%$ atau 0,05 . Bila $\rho$ (Value) $\geq \alpha(0,05)$ maka Ho ditolak, artinya tidak ada pengaruh yang signifikan antara variable dependent dan variable independent. Apabila $\rho$ (Value) $\leq$ 0,05 maka $\mathrm{Ha}$ diterima, artinya ada pengaruh yang signifikan antara variable dependent dan variable independent.

2. Analisa Multivariat

Analisis Multivariat dalam penelitian ini dilakukan dengan menguji secara bersama-sama keseluruhan variable independent untuk melihat variable mana yang paling berpengaruh terhadap variable dependent dengan menggunakan uji regresi logistic. Variable yang akan di ikutsertakan dalam analisis multivariate adalah variable yang mempunyai $\rho$ (Value) $\leq 0,05$.

\section{HASIL PENELITIAN}

1. Analisis Univariat

Tabel 1 karakteristik Responden Perawat di di Puseksmas Akreditasi dan Non Akreditasi Tahun 2018. $(n=121)$

\begin{tabular}{|l|l|l|l|l|}
\hline Karakteristik & \multicolumn{1}{|c|}{$\mathrm{n}$} & \multicolumn{1}{|c|}{$\%$} & $\mathrm{n}$ & \multicolumn{1}{c|}{$\%$} \\
\hline Umur & & & & \\
$21-40$ & 2 & 3,9 & 7 & 10,0 \\
$41-60$ & 19 & 37,3 & 34 & 48,6 \\
$61-80$ & 25 & 49,0 & 23 & 32,9 \\
& 5 & 9,8 & 6 & 8,6 \\
\hline Jenis & & & & \\
Kelamin & & & & \\
Laki-Laki & 24 & 47,1 & 32 & 45,7 \\
Perempuan & 27 & 52,9 & 38 & 54,3 \\
\hline Pekerjaan & & & & \\
IRT & 18 & 35,3 & 3 & 4,3 \\
Wiraswasta & 14 & 27,5 & 29 & 41,4 \\
PNS & 3 & 5,9 & 20 & 28,6 \\
Honorer & 2 & 3,9 & 1 & 1,4 \\
Karyawan & 0 & 0 & 3 & 4,3 \\
Petani & 11 & 21,6 & 8 & 11,4 \\
Pelajar & 1 & 2,0 & 6 & 8,6 \\
Sopir & 2 & 3,9 & $\mathbf{0}$ & $\mathbf{0}$ \\
\hline Pendidikan & & & & \\
SD & 17 & 33,3 & 21 & 30,0 \\
SMP & 11 & 21,6 & 6 & 8,6 \\
SMA & 18 & 35,3 & 39 & 55,7 \\
Diploma & 2 & 3,9 & 2 & 2,9 \\
Sarjana & 3 & 5,9 & 2 & 2,9 \\
\hline
\end{tabular}

Tabel 1. diketahui bahwa distibusi karakteristik responden di puskesmas non akreditasi berdasarkan umur responden menunjukkan bahwa dari 51 responden, pada usia produktif 41 - 60 Tahun lebih banyak yaitu 25 responden $(49,0 \%)$ dibandingkan usia muda <=20 sebanyak 2 responden (3,9\%). Berdasarkan jenis kelamin mayoritas jenis kelamin perempuan sebanyak 27 $(52,9 \%)$ dan laki-laki sebanyak 24 $(47,1 \%)$. Selanjutnya distribusi tingkat pekerjaan responden yang terbanyak adalah IRT sebanyak 18 responden 
(35,3\%). Distribusi tingkat pendidikan responden yang paling banyak adalah tingkat pendidikan SMA sebanyak 18 responden $(35,3 \%)$. Sedangkan distribusi karakteristik responden puskesmas terakreditasi menunjukkan bahwa dari 70 responden, pada usia produktif 21 - 40 Tahun lebih banyak yaitu 35 responden $(48,6 \%)$ dibandingkan usia lanjut 61- 80 sebanyak 6 responden (8,6\%). jenis kelamin perempuan sebanyak $38(54,3 \%)$ dan laki-laki sebanyak 32 (45,7\%).

Selanjutnya distribusi tingkat pekerjaan responden yang terbanyak adalah IRT sebanyak 29 responden $(41,4 \%)$ dikarenakan banyak responden lebih banyak perempuan dan yang paling sedikit sebanyak 1 responden $(1,4 \%)$ dengan status PNS. Distribusi tingkat pendidikan responden yang paling banyak adalah tingkat pendidikan SMA sebanyak 39 responden $(55,7 \%)$.

\section{Analisis Bivariat}

Tabel 2. Distribusi tentang persepsi pasien terhadap kualitas pelayanan di Puskesmas Akreditasi dan Non AkreditasTahun 2018

\begin{tabular}{|c|c|c|c|c|c|c|c|c|}
\hline \multirow{4}{*}{$\begin{array}{l}\text { Kualitas } \\
\text { Pelayana } \\
\text { D }\end{array}$} & \multirow{2}{*}{\multicolumn{4}{|c|}{$\frac{\text { Puskesmas Non Akreditasi }}{\text { Persepsi Pasien }}$}} & \multicolumn{4}{|c|}{ Puskesmas Akreditasi } \\
\hline & & & & & \multicolumn{4}{|c|}{ Persepsi Pajen } \\
\hline & \multirow{2}{*}{$\begin{array}{l}\text { Tidak } \\
\text { Puas } \\
\mathrm{n}(\%)\end{array}$} & \multirow{2}{*}{$\begin{array}{l}\text { Puas } \\
\mathrm{n}(\%) \\
\end{array}$} & \multicolumn{2}{|c|}{ Total } & $\begin{array}{l}\text { Tidak } \\
\text { Puas }\end{array}$ & Puas & & \\
\hline & & & $\mathrm{n}$ & $\%$ & $n(\%)$ & $n(\%)$ & $n$ & $\%$ \\
\hline \multicolumn{9}{|l|}{ Assuranc } \\
\hline Kurang & $6(100)$ & 0 & 6 & $\begin{array}{c}10 \\
0\end{array}$ & 0 & $1(100)$ & 1 & $\begin{array}{c}10 \\
0\end{array}$ \\
\hline Cukup & $2(4,4)$ & $\begin{array}{c}43 \\
(95,6)\end{array}$ & $\begin{array}{l}4 \\
5 \\
\end{array}$ & $\begin{array}{c}10 \\
0 \\
\end{array}$ & $\begin{array}{c}10 \\
(14,5)\end{array}$ & $\begin{array}{c}59 \\
(85,5)\end{array}$ & 69 & $\begin{array}{c}10 \\
0\end{array}$ \\
\hline \multicolumn{5}{|c|}{$\mathrm{P}=0,00$} & \multicolumn{4}{|c|}{$P=0,00$} \\
\hline \multicolumn{9}{|l|}{ Emphaty } \\
\hline Kurang & $\begin{array}{c}6 \\
(75,0)\end{array}$ & $2(25,0)$ & 8 & $\begin{array}{c}10 \\
0\end{array}$ & $\begin{array}{c}1 \\
(33,3)\end{array}$ & $2(66,7)$ & 3 & $\begin{array}{c}10 \\
0\end{array}$ \\
\hline Cukup & $2(4,7)$ & $\begin{array}{c}41 \\
(95,3)\end{array}$ & $\begin{array}{l}4 \\
5\end{array}$ & $\begin{array}{c}10 \\
0\end{array}$ & $\begin{array}{c}9 \\
(13,4)\end{array}$ & $\begin{array}{c}58 \\
(86,6)\end{array}$ & 67 & $\begin{array}{c}10 \\
0\end{array}$ \\
\hline \multicolumn{5}{|c|}{$P=0,00$} & \multicolumn{4}{|c|}{$P=0,00$} \\
\hline
\end{tabular}

Berdasarkan tabel 2. varibel assurance pada puskesmas non akreditasi menunjukkan bahwa persepsi pasien merasa tidak puas lebih banyak (100\%) dibandingkan pada puskesmas akreditasi. variable emphaty pada puskesmas non akreditasi menunjukkan bahwa persepsi pasien merasa tidak puas lebih banyak $(75,0 \%)$ dibandingkan pada puskesmas akreditasi bahwa persepsi pasien merasa tidak puas $(33,3 \%)$.

\section{PEMBAHASAN}

Berdasarkan tabel 2 variabel tangible terhadap persepsipasien di puskesmas non akreditasi menunjukkan bahwa responden yang merasa kurang dan merasa tidak puas berjumlah 6 responden $(85,7 \%)$, kategori yang merasa cukup dan pasien yang merasa puas berjumlah 42 responden $(95,5 \%)$. Sedangkan pada variabel tangible terhadap persepsipasien di puskesmas akreditasi menunjukkan bahwa dari responden yang merasa kurang dan kepuasan pasien merasa tidak puas berjumlah 5 responden $(62,5 \%)$ dan pasien yang merasa cukup dan merasa puas berjumlah 57 responden $(91,9 \%)$.

1. Assurance (jaminan) berdasarkan persepsi pasien.

Berdasarkan tabel 2. variabel assurance terhadap persepsipasien di puskesmas non akreditasi menunjukkan bahwa responden yang merasa kurang dan merasa tidak puas berjumlah 6 responden $(100 \%)$, kategori yang merasa cukup dan pasien yang merasa puas berjumlah 43 responden $(95,6 \%)$. Sedangkan pada variabel assurance terhadap persepsipasien di puskesmas akreditasi menunjukkan bahwa tidak ada responden yang merasa kurang dan kepuasan pasien merasa tidak puas dan pasien yang merasa cukup dan merasa puas berjumlah $59(85,5 \%)$ responden

Berdasarkan tabel deskripsi kuisioner tentang assurance pada Tabel 2. Menunjukkan pada puskesmas non akreditasi pasien yang merasa kurang lebih banyak $(11,8 \%)$ dalam hal petugas teliti memberikan informasi obat dibandingkan pada puskesmas akreditasi yang pasien merasa kurang $(1,4 \%)$ Artinya petugas yang ada di puskesmas dalam memeriksa pasien masih kurang dalam hal pemberian informasi penggunaan dosis obat kadangkala pasien masih kebinggungan dalam pemakaian obat.

Berdasarkan hasil uji regresi sederhana didapatkan hasil $\rho=0,000<\alpha$, dengan demikian hipotesis Ho ditolak dan $\mathrm{Ha}$ diterima. Yang mengatakan bahwa adanya pengaruh Variabel Assurance terhadap persepsipasien di puskesmas akreditasi dan non akreditasi kab. Banggai tahun 2018.

Hal ini sesuai dengan pendapat Fadlan, (2014), jaminan dan kepastian merupakan mampu memberikan informasi kepada pelanggan dalam bahasa yang dapat mereka pahami, aman dari bahaya, resiko atau keragu- raguan, memiliki keterampilan dan pengetahuan yang dibutuhkan agar dapat memberikan jasa tertentu. Penelitian ini juga sejalan dengan penelitian yang dilakukan oleh rahayu 2013) Pengaruh assurance terhadap kepuasan konsumen Berdasarkan hasil analisis data diperoleh kesimpulan ada 
pengaruh yang positif dan signifikan assurance terhadap kepuasan konsumen. bahwa konsumen akan merasa puas dengan kualitas pelayanan assurance yang diberikan kepada konsumen berupa perusahaan mampu menunjukkan aspek legal kepada konsumen, perusahaan mengutaman jaminan dalam memberikan spesifikasi dan perusahaan mampu menanamkan kepercayaan kepada para konsumen. Penelitian yang dilakukan oleh Mukminin (2013) mengatajan bahwa faktor Assurance yang memiliki hubungan yang kuat, untuk mengungkap kepuasan konsumen Masing masing faktor memberikan konstribusi yang berbeda beda apabila di rangking, faktor yang konstribusinya paling tinggi adalah faktor responsiveness, diikuti dengan assurance,

Penelitian ini juga mendukung hasil temuan Wibowo (2011) dalam penelitiannya tentang kualitas pelayanan terhadap kepuasan, menemukan bahwa kinerja kulaitas secara langsung dapat meningkatkan kepuasan. Produk dalam penelitian ini adalah kualitas layanan, walaupun dalam penelitian in tidak di lakukan secara khusus menyangkut kinerja pelayanan, tetapi secara umum bisa di simpulkan bahwa tingkat kepuasan yang dialami/dirasakan oleh pelanggan, Sehingga dapat di artikan secara ringkas kepuasan pelanggan ini akan muncul apabila layanan yang di berikan sesuai dengan kualitas yang di harapkan oleh pelanggan.

Diperkuat oleh Permenkes No 28 Tahun 2014 Jaminan (assurance) yakni mencakup pengetahuan, keterampilan, mampu menumbuhkan kepercayaan pasiennya. Jaminan juga berarti bahwa bebas bahaya, risiko dan keragu-raguan. Menurut Kotler, (2000). Kepuasan konsumen adalah hasil yang di rasakan oleh pembeli yang mengalami kinerja sebuah perusahaan yang sesuai dengan harapannya. Pasien merasa puas kalau harapan mereka untuk sembuh terpenuhi dan sesuai dengan jaminan kesembuhan yang diberikan oleh pihak rumah sakit, dan merasa amat gembira kalau harapan untuk sembuh dapat mereka rasakan, bukan hanya puas saja, pasien yang puas cenderung tetap loyal dan memicu minat kebali, begitupun sebaliknya jika yang dirasakan oleh oleh pasien tidak tidak sesuai dengan yang diharapkan atau yang di janjikan oleh oleh pihak pemeberi layanan maka pasien akan merasa tidak puas dan pasien bahkan tidak merekomendasikan untuk dirinya dan keluarga untuk kembali ke pusat pelayanan tersbut. Kepuasan konsumen merupakan hasil evaluasi konsumen yang menggunakan barang atau jasa yang mana sesuai dengan harapan yang di inginkan oleh konsumen tersebut dan secara alami akan menggunakan barang atau jasa tersebut kembali. Hal ini kiranya benar adanya karena orang dapat di katakan puas apabila apa yang di dapatkan lebih besar dari apa yang di harapkan atau sesuai dengan yang di janjikan (assurance).

2. Emphaty (perhatian) berdasarkan Persepsi Pasien

Berdasarkan table 2. variabel empathy terhadap persepsipasien di puskesmas non akreditasi menunjukkan bahwa responden yang merasa kurang dan merasa tidak puas berjumlah 6 responden $(75,0 \%)$, kategori yang merasa cukup dan pasien yang merasa puas berjumlah 41 responden (95,3\%). Sedangkan pada variabel emphaty terhadap persepsipasien di puskesmas akreditasi menunjukkan bahwa dari responden yang merasa kurang dan kepuasan pasien merasa tidak puas berjumlah 1 responden $(33,3 \%)$ dan pasien yang merasa cukup dan merasa puas berjumlah 58 responden $(86,6 \%)$

Berdasarkan tabel deskripsi kuisioner tentang emphaty pada Tabel 2. menunjukkan pada puskesmas non akreditasi pasien yang merasa kurang lebih banyak $(15,7 \%)$ dalam hal sabar dalam menghadapi pasien dibandingkan pada pasien yang merasa kurang di puskesmas akreditasi (4,3\%). Artinya petugas kesehatan kurang memberikan ketenangan dalam hati pasien tentang riwayat penyakit pasien, petugas kurang menanyakan keluhan pasien apa yang dirasakan setelah dilakukan pengobatan dari para petugas di puskesmas.

Berdasarkan hasil uji regresi sederhana didapatkan hasil $\rho=0,000<\alpha$, dengan demikian hipotesis Ho ditolak dan $\mathrm{Ha}$ diterima. Yang mengatakan bahwa adanya pengaruh Variabel Emphaty terhadap persepsipasien di puskesmas akreditasi dan non akreditasi kab. Banggai tahun 2018

Penelitian ini sejalan dengan penelitian yang dilakukan oleh Nurul (2018), ada hubungan yang signifikan antara kualitas pelayanan empati dengan kepuasan pasien, Empati (empathy) merupakan persepsi pasien yang dinilai berdasarkan kesopanan dan keramahan 
pemberian layanan secara individu dengan penuh perhatian dan memahami kebutuhan pasien sebagai pelanggan dan bertindak demi kepentingan pasien dan senangtiasa membantu pasien walau tidak diminta. Penelitian serupa juga dilakukan oleh Bilqis, dirumah sakit pendidikan Nigeria.

Peneliatian ini mendukung penelitian yang dilakukan oleh Rahayu (2013), Pengaruh empathy terhadap kepuasan konsumen Berdasarkan hasil analisis data diperoleh kesimpulan ada pengaruh yang positif dan signifikan empathy terhadap kepuasan pasien. Hal tersebut dapat peneliti jelaskan bahwa pasien akan merasa puas dengan kualitas pelayanan empathy yang diberikan petugas berupa perusahaan mampu menunjukkan aspek legal kepada konsumen, perusahaan mengutaman empathy.

Penelitian ini juga memperkuat penelitian yang dilakukan oleh antin (2009) Perhatian pelayanan yang ditunjukkan oleh petugas kesehatan ditanggapi dengan baik dan sudah sesuai dengan harapan pasien. Oleh karena itu faktor ini penting untuk dipertahankan, karena aspek dari perilaku petugas kesehatan seperti pemberian informasi tentang penyakit pasien disertai dengan keterbukaan dalam berdiskusi tentang penyakitnya, merupakan faktor-faktor yang mempengaruhi kualitas pelayanan kesehatan. Tjiptono (2000) menyebutkan bahwa kepuasan pelanggan memiliki hubungan yang erat dengan kualitas. Kualitas akan memberikan suatu dorongan kepada pelanggan untuk menjalin ikatan hubungan yang kuat dengan penyelenggara produk/jasa.

Menurut riyadi (2017), empati (empathy) merupakan persepsi pasien yang dinilai berdasarkan kesopanan dan keramahan pemberian layanan secara individu dengan penuh perhatian dan memahami kebutuhan pasien sebagai pelanggan dan bertindak demi kepentingan pasien dan senantiasa membantu pasien walau tidak diminta. Pasien akan merasa diperhatikan oleh petugas kesehatan jika apa yang dibutuhkan dan dikeluhkannya ditanggapi secara baik oleh pihak petugas kesehatan, dan sikap yang tulus dan berifat individual atau pribadi yang diberikan petugas kesehatan kepada pasien seperti kemudahan untuk menghubungi petugas kesehatan, kemampuan petugas kesehatan untuk berkomunikasi dengan pasien dan keluarga pasien. Semakin baik persepsi petugas kesehatan terhadap kepedulian (empathy) maka kepuasan pasien akan semakin tinggi. Dan jika persepsi pasien terhadap kepedulian (empathy) buruk, maka kepuasan pasien akan semakin rendah. Sejalan dengan penelitian yang dilakukan Atmawati dan Wahyudin (2007) menyebutkan bahwa variabel kepedulian (empathy) berpengaruh positif terhadap kepuasan pasien. Perhatian petugas kesehatan yang dapat dilihat dari kepeduliannya pada setiap keluhan pasien dan keluarganya, ditanggapi dengan baik oleh pasien. Hal ini berarti bahwa faktor kepedulian petugas kesehatan sudah memenuhi harapan pasien. petugas kesehatan pada pasien mempengaruhi mutu pelayanan kesehatan. Dimana mutu pelayanan merupakan penentu kepuasan pelanggan. Selanjutnya faktor-faktor yang dinilai berlebihan oleh pasien, karena pasien menganggap faktor tersebut tidak terlalu penting, akan tetapi pelaksanaannya telah dilakukan dengan baik yakni faktor petugas kesehatan melayani semua pasien tanpa memandang status sosial ekonomi

\section{KESIMPULAN}

1. Ditemukan adanya pengaruh yang signifikan antara persepsi pasien dengan kualitas assurance di puskesmas akreditasi dan non akreditasi kab. banggai.

2. Ditemukan adanya pengaruh yang signifikan antara persepsi pasien dengan kualitas Empathy di puskesmas akreditasi dan non akreditasi kab. banggai.

\section{SARAN}

1. Diharapkan kepada pihak Puskesmas yang telah akreditasi dan puskesmas yang belum terakreditasi agar tetap mempertahankan pelayanan yang diberikan guna untuk mendapatkan kepuasan yang optimal kepada seluruh pasien yang menjalankan perawatan di Ruang rawat Inap puskesmas.

2. Diharapkan kepada pihak manajemen puskesmas yang terakreditasi dan puskesmas yang belum terakreditasi karena semakin tingginya tingkat kepuasan pasien diharapkan untuk kedepanya bisa memberikan pelayanan yang melebihi keinginan pelanggan 


\section{DAFTAR PUSTAKA}

Ardian, Adhiatma, 2011.Analisis Kepuasan Konsumen Terhadap Kualitas Pelayanan Jasa Kesehatan Di Rumah Sakit Ibu dan Anak Di Semarang, Vol.2, No.2 : 67-76.

Kemenkes UNDANG-UNDANG REPUBLIK INDONESIA NOMOR 36 TAHUN 2009 TENTANG KESEHATAN

Khusnawati. 2012. Analisis Kepuasan Pasien terhadap Pelayanan pada Puskesmas Sungai Durian, Kab.Kubu Raya. Skripsi sarjana. Fakultas Kesehatan Masyarakat. Universitas Hasanuddin, Makassar.

Kotler, Philip. 2012. prinsip-prinsip Pemasaran, edisi II, Indeks: Jakarta Erlangga.

Kotler, Phillip, Kevin Lance Keller. 2012. Marketing Management 14th edition. Jakarta:PT. Indeks Kelompok Gramedia.

Kotler, Phillip dan Kevin L. Keller. 2013. Marketing Management Horizon edition. New Jersey: Pearson.

Mawarti Fitri, dkk, 2015. Analisis Kualitas Pelayanan Puskesams Terhadap Kepuasan Ibu Hamil DI Kota Pangkal Pinang. Program Pascasarjana Kesehatan Masyarakat, Universitas Srawijaya, Provinsi Sumatera Selatan, Palembang.

Mirshanti Farahdila,2017. Pengaruh Status Akreditasi Puskesmas, Faktor Sosial Ekonomi dan Jenis Asuransi Pasien Terhadap Kualitas Pelayanan Dan Kepuasan Pasien di Puskesmas, Progam Pasca Sarjana, Program Studi Magister Kesehatan Masyarakat. Universitas Sebelas Maret, Surakarta.

Notoatmodjo, S. 2007. Promosi Kesehatan dan Ilmu Perilaku. Jakarta: Rineka Cipta.

Notoadmodjo Soekidjo, 2010. Kesehatan Masyarakat IImu dan Seni, Penerbit Rineka Cipta, Jakarta.

Parasuraman, A, Valerie A. Zeithaml, Leonard L. Berry. 1998 SERVQUAL : A Multiple Item Scale For Measuring Consumer Perception Of Service Quality. Journal Of Retailing Vol. 64 No. 1, pp 12-37.

Pedoman Penulisan Tesis Dan Disertasi, 2014. Program Pascasarjana Universitas Muslim Indonesia, Makassar. Profil Dinas Kesehatan Kab. Banggai,2017. Jumlah Kunjungan Rawat Jalan Dan Rawat Inap Disaran Fasilitas Kesehatan Kab. Banggai, Luwuk.

Pratiwi, Kartika Gita. dkk. 2014. Analisis Mutu Pelayanan Rumah Sakit dan Pengaruhnya Terhadap Kepuasan Pasien Rumah Sakit Ibu dan Anak (RSIA) Andini di Pekan Baru, Vol. 1 No. 2 hal. 2.

Riyadi Akal, 2017. Hubungan Status Akreditasi Puskesmas Dengan Tingkat Kepuasan Pasien Di Puskesmas Kabupaten Bantul, Sekolah Tinggi Ilmu Keperawatan Jendral Ahmad Yani. Yogyakarta.

Trisnawati, Komang. 2015. Analisis kepuasan pasien rawat jalan Pns Pada Masa Pelaksanaan Askes Dan Jkn Di Rsup Dr.sardjito Yogyakarta. Tesis, Universitas Gajah Mada, Yogyakarta, Indonesia.

Trimurthy Iga, 2008. Analisis Hubungan Presepsi Pasien Tentang Mutu Pelayanan Dengan Minat Pemanfaatan Ulang Pelayanan Rawat Jalan Puskesmas Pandanaran Kota Semarang. Program Studi Magister IImu Kesehatan Masyarakat Konsentrasi Administrasi Kebijakan Kesehatan, Program Pascasarjana Universitas Diponegoro, Semarang.

Wahyu Kuntoro,dkk,2017. Kepuasan Pasien Terhadap Kualitas Pelayanan di Tempat Pendaftaran Pasien Rawat Jalan Puskesmas Kretek Bantul Yogyakarta. Fakultas Kedokteran Universitas Gaja Mada. Yogyakarta.

Wardani Ratna,2012. Analisa Kepuasan Pasien Di Tinjau Dari Kualitas Pelayanan Kesehatan Setelah Terakreditasi Paripurna. Komisi Akreditasi Puskesmas (KARS) 2017, Tulungagung Provinsi Jawa Timur.Surabaya. 